\title{
Miniaturized Dual-Band Aperture Coupled Microstrip Antenna Using Corrugated Ground
}

\author{
Minquan $L I^{1}$, Kun $Q^{\prime} N^{1}$, Hongqing $H E^{1}$ \\ ${ }^{1}$ Key Laboratory of Intelligent Computing and Signal Processing, Ministry of Education, \\ Anhui University, Hefei 230039, China \\ limq@ahu.edu.cn,604766289@qq.com, hqhemeet@163.com
}

Manuscript received December 20, 2015

\begin{abstract}
A novel dual-band aperture coupled microstrip antenna with corrugated ground plane is proposed to improve radiation performance in this letter. The dual-band operation is obtained by embedding an S-shaped slot in the radiating patch. To achieve the high gain and the reduced half power beam bandwidth (HPBW) for each frequency, the double-periodic corrugated ground plane is utilized. Both the simulation and measurement results show that the gain of the proposed antenna is increased by $4.7 \mathrm{~dB}$ and $5.6 \mathrm{~dB}$ at each frequency correspondingly and the half power beam width (HPBW) of E-plane is reduced by 140 degrees and 150 degrees, respectively.
\end{abstract}

\section{Keywords}

Microstrip antenna, dual-band, aperture coupled, corrugated ground plane

\section{Introduction}

Dual-band microstrip antenna is very suitable in modern communication systems and plays a vital role in many practical applications for its small size, low profile and light weight. In many practical applications, the systems are desired to operate in two distinct frequencies efficiently [1] and a variety of dual-band microstrip antennas have been designed to satisfy the requirement [2-4]. Nevertheless, the dual-band microstrip antennas often suffer from low gain and poor directivity. Innovative design should be further investigated to improve the radiation performance of this kind of antenna.

The enhanced transmission phenomenon was firstly found at the optical range by T. W. Ebbesen [5]. It has been demonstrated that this phenomenon can be applied to the design of microwave antenna for improved performance [6-9]. In [6], a bull's eye corrugated structure is used as the ground plane of a patch antenna. By modulating the bull's eye corrugated plate, a novel patch antenna with high gain and narrow beam-width is proposed. In [7], the horn antenna with high gain and narrow radiated beam is obtained by a double-periodic corrugated metallic plate. Since the upper operating frequency of this antenna is determined by the metallic plate thickness, the profile of the antenna is $12 \mathrm{~mm}$. Subsequently, a dielectric material with relative permittivity $\varepsilon_{\mathrm{r}}>1$ is inserted into the grooves [8], and then the profile of this antenna can be further reduced.

In our previous investigation, a novel aperture-coupled microstrip antenna with enhanced gain and radiation pattern is obtained by using the corrugated ground plane [9]. To meet the dual-band operation requirement, a novel dual-band microstrip antenna with improved radiation performance is presented in this paper. The proposed dualband antenna is designed by embedding an S-shaped slot in the radiating patch and double periodic corrugated ground plane. The physical mechanisms of improved performance are investigated by analyzing the electric field distribution of the proposed antenna.

\section{Antenna Configuration and Design}

The layout of the proposed dual-band microstrip antenna is shown in Fig. 1. It consists of two parallel Rogers RT5880 substrates separated by a double-periodic corrugated ground plate. In order to obtain the dual-band radiation, an S-shaped slot is embedded in the radiating patch. The aperture coupling is used to feed the antenna. By etching the grooves with different periodic in the ground plane symmetrically, the coherent superposition of radiated electric fields for each frequency is generated. To demonstrate the superiority of the proposed antenna, a conventional antenna with a flat ground plane is also analyzed as shown in Fig. 1a.

Based on our previous investigation in [9], the initial dimensions of the double-periodic corrugated ground plane can be estimated using (1). In (1), $\lambda_{i}$ is the free space wavelength at each operated frequency, $\varepsilon_{\mathrm{r}}$ is the relative dielectric constant of the substrate. The final optimized dimensions of the proposed antenna are tabulated in Tab. 1. 


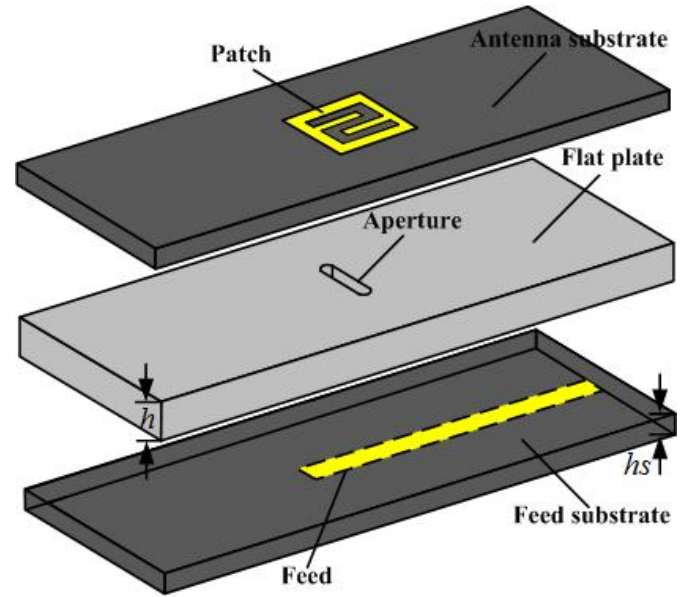

Fig. 1a. Front view of the conventional antenna.

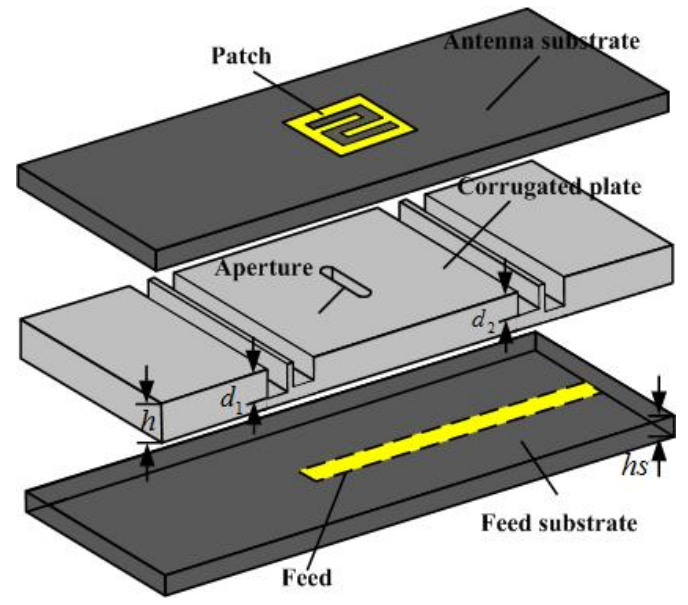

Fig. 1b. Front view of the proposed antenna.

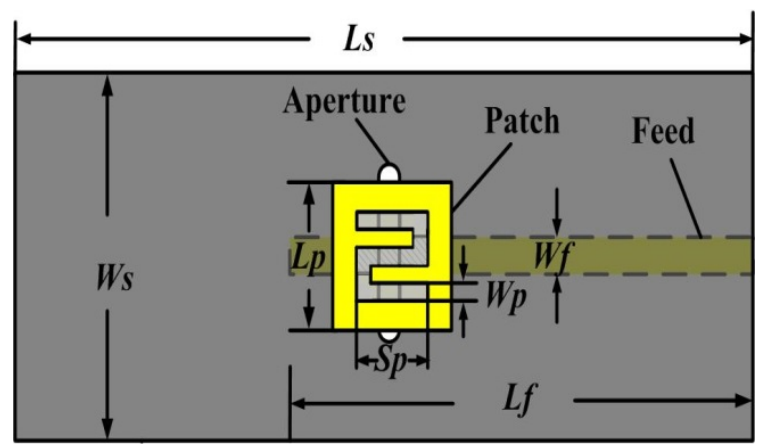

Fig. 1c. Top view of the proposed antenna.

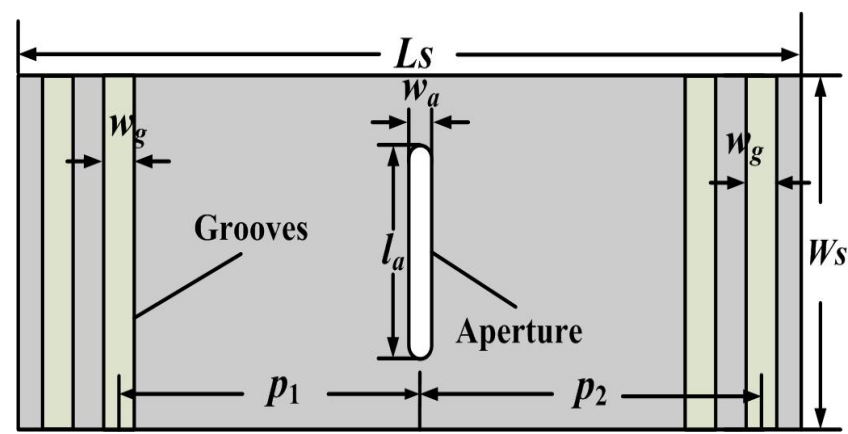

Fig. 1d. Top view of the corrugated plate.

\begin{tabular}{|l|c|c|c|c|c|c|}
\hline Parameter & $\boldsymbol{L s}$ & $\boldsymbol{W} \mathbf{s}$ & $\boldsymbol{L p}$ & $\boldsymbol{W p}$ & $\boldsymbol{S p}$ & $\boldsymbol{L f}$ \\
\hline Value $/ \mathbf{m m}$ & 60 & 24 & 3.4 & 0.3 & 2.3 & 33 \\
\hline Parameter & $W \mathrm{f}$ & $h \mathrm{~s}$ & $h$ & $l_{\mathrm{a}}$ & $w_{\mathrm{a}}$ & $p_{1}$ \\
\hline Value $/ \mathbf{m m}$ & 1.5 & 0.5 & 4 & 8 & 1.5 & 12 \\
\hline Parameter & $p_{2}$ & $d_{1}$ & $d_{2}$ & $w_{\mathrm{g}}$ & $/$ & $/$ \\
\hline Value $/ \mathbf{m m}$ & 15 & 2.5 & 3 & 2.5 & $/$ & $/$ \\
\hline
\end{tabular}

Tab. 1. Dimensions of the proposed antenna.

$$
\left\{\begin{array}{l}
w_{\mathrm{g}}<\frac{\lambda_{i}}{\sqrt{\varepsilon_{\gamma}}}, \quad i=1,2, \\
p_{i} \approx \frac{\lambda_{i}}{\sqrt{\varepsilon_{\gamma}-1}}, \quad i=1,2, \\
d_{i} \approx \frac{\lambda_{i}}{1 / 2\left[\varepsilon_{\mathrm{r}}+1+\left(\varepsilon_{\mathrm{r}}-1\right)\left(\sqrt{1+\frac{12 h}{w}}\right)\right]}, \quad i=1,2, \\
h \approx \frac{1}{4} \frac{\lambda_{1}+\lambda_{2}}{\sqrt{\varepsilon_{\gamma}}} .
\end{array}\right.
$$

\section{Implementation and Discussion}

The surface electric field distributions on the patch for both operated frequencies are shown in Fig. 2. By comparing Fig. 2a with Fig. 2b, it is found that the surface electric field distribution is different at each operating frequency [2]. This implies the dual-band operations are dependent on the corresponding part of the radiating patch.

The photograph of the fabricated antenna with the corrugated plate is shown in Fig. 3.The simulated and measured reflection coefficients of the proposed antenna and conventional antenna are given in Fig. 4. A good agreement can be observed between the measurement and simulation. Little frequency discrepancy may be due to the fabrication tolerance.

The radiation patterns at the resonant frequencies of both antennas are shown in Fig. 5 and Fig. 6, respectively. A good agreement between the measurement and simulation is obtained for both E-plane and H-plane. As illustrated in Fig. 5 and Fig. 6, the gains of the proposed antenna are increased by $4.7 \mathrm{~dB}$ and $5.6 \mathrm{~dB}$, and the HPBW of E-plane are reduced by 140 degrees and 130 degrees, demonstrating the validity of our proposed design. (a)

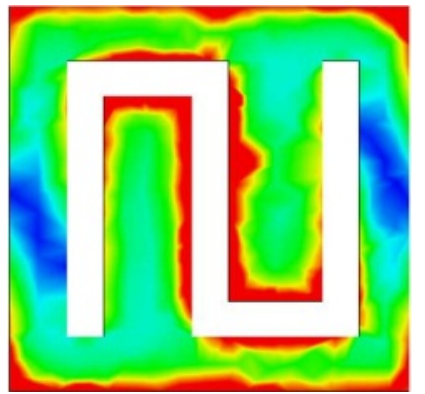

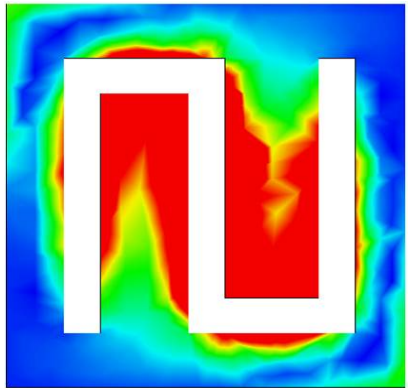

(b)
Fig. 2. Surface electric field distribution on the S-shaped slotted patch at: (a) $13 \mathrm{GHz}$, (b) $16.5 \mathrm{GHz}$. 

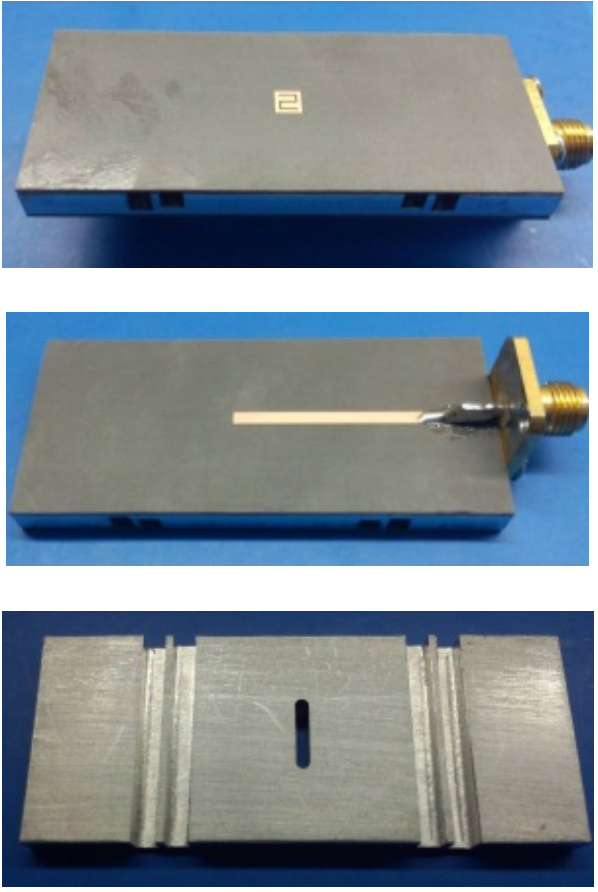

Fig. 3. The fabricated new antenna: (a) Top view. (b) Bottom view. (c) Fabricated corrugated ground plane.

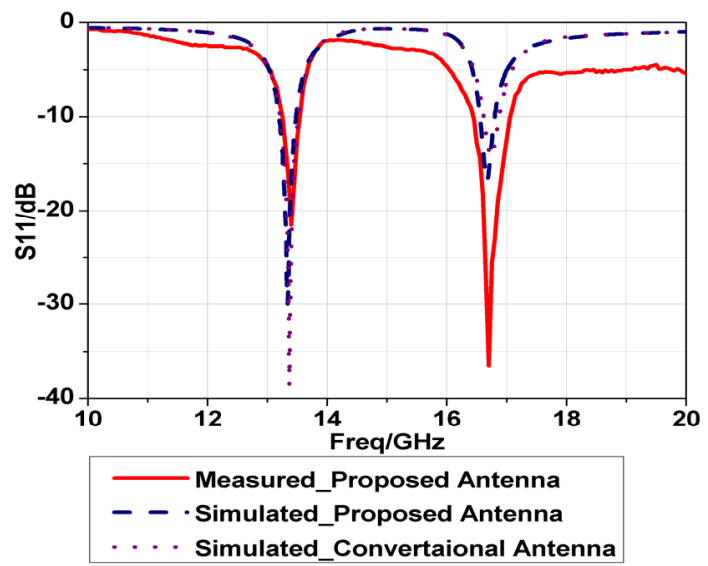

Fig. 4. Simulated and measured reflection coefficients of the proposed antenna.

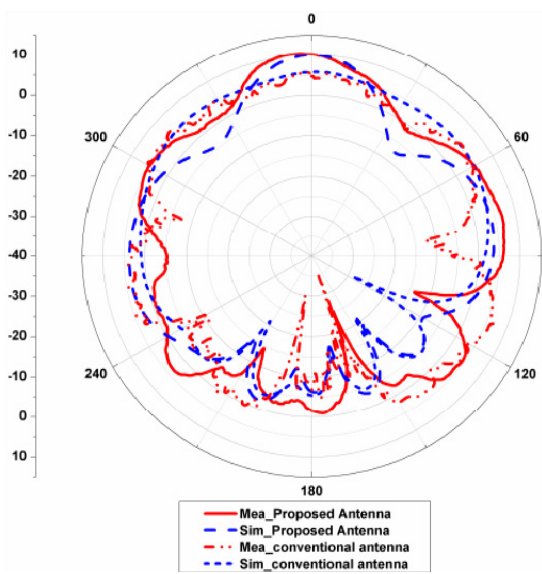

Fig. 5a. Simulated and measured E-plane far-field radiation patterns of the proposed antenna and conventional antenna at $13 \mathrm{GHz}$.

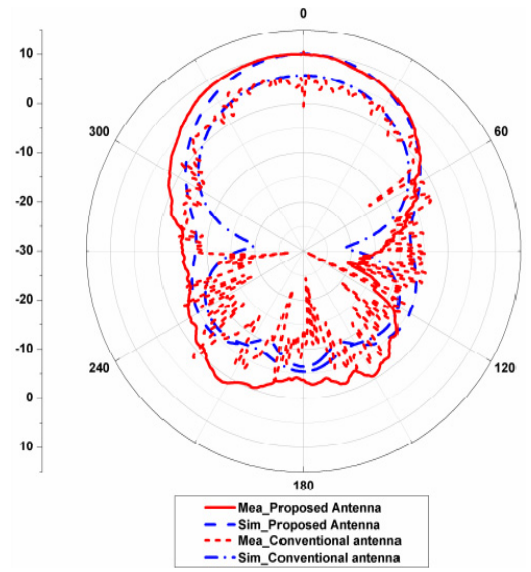

Fig. 5b. Simulated and measured H-plane far-field radiation patterns of the proposed antenna and conventional antenna at $13 \mathrm{GHz}$.

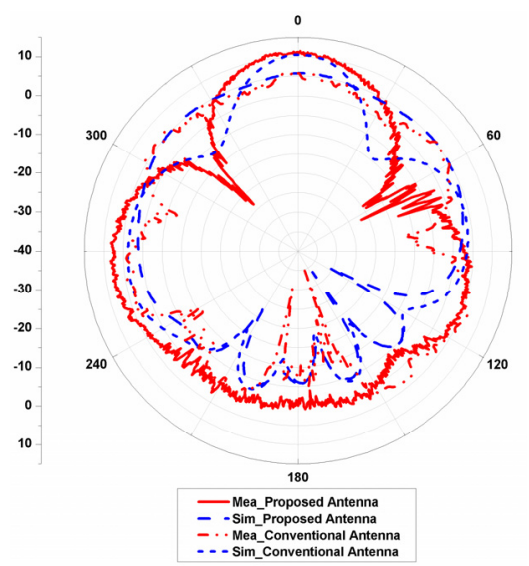

Fig. 6a. Simulated and measured E-plane far-field radiation patterns of the proposed antenna and conventional antenna at $16.5 \mathrm{GHz}$

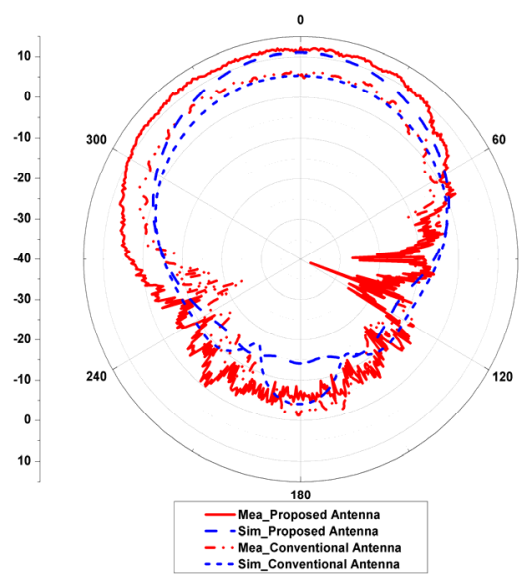

Fig. 6b. Simulated and measured H-plane far-field radiation patterns of the proposed antenna and conventional antenna at $16.5 \mathrm{GHz}$.

Table 2 shows the comparison of the proposed antenna and the antenna in [7]. It is seen that the proposed antenna can achieve slightly better improved radiation performance with reduced profile. The Rogers RT5880 substrate $\left(\varepsilon_{\mathrm{r}}=2.2\right)$ loaded on the corrugated plate may excite more surface wave [10]. Thus, the better improved 


\begin{tabular}{|c|c|c|c|c|}
\hline Antenna & Operating Frequency(GHz) & Improvement of Gain/dB & HPBW/deg & Profile/mm \\
\hline Reference & 13 & 4.4 & 40 & \multirow{2}{*}{12} \\
\cline { 2 - 4 } Antenna in [7] & 16.5 & 4.5 & 60 & \\
\hline \multirow{2}{*}{$\begin{array}{c}\text { Proposed } \\
\text { Antenna }\end{array}$} & 13 & 4.7 & 23 & \multirow{2}{*}{5} \\
\cline { 2 - 4 } & 16.5 & 5.6 & 21 & \\
\hline
\end{tabular}

Tab. 2. Comparison for the proposed antenna with other designs.

performance can be explained. For the reference antenna in [7], the upper operating frequency $(16.5 \mathrm{GHz})$ is in a similar manner as a Fabry-Perot resonator, which is determined by the thickness of metallic plate $(12 \mathrm{~mm})$ [7]. While for the proposed antenna in this paper, the dual-band characteristic is achieved by cutting an S-shaped from the patch, without increasing the profile of this antenna $(5 \mathrm{~mm})$. The profile of the proposed antenna is reduced to $0.217 \lambda_{1}$ and $0.275 \lambda_{2}$.

In our previous investigation, the improved performance of the proposed antenna can be explained as the constructive superposition of the radiated electric fields [9]. For the conventional antenna, the power is radiated into free space through the patch at each operating frequency as shown in Fig. 7a and Fig. 7c. While for the proposed antenna, the power radiated from the patch is considered as the primary source and the corrugated grooves can be regarded as the secondary sources. When the grooves' periods are close to the wavelengths of each reso-

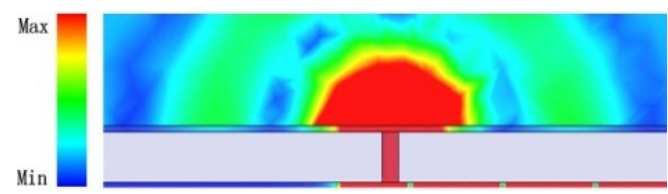

(a)

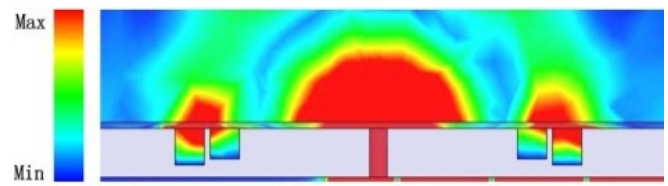

(b)

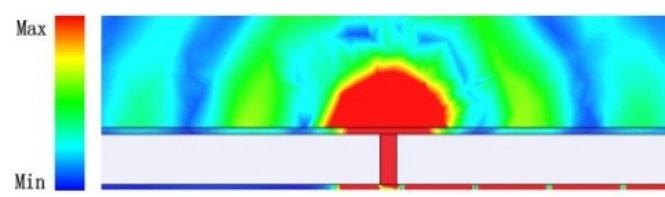

(c)

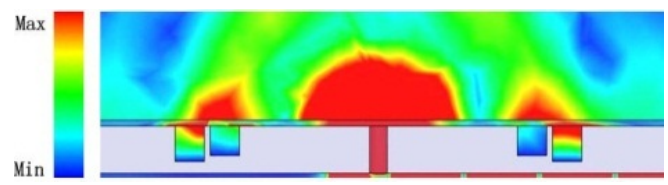

(d)

Fig. 7. The instantaneous electric field strength distribution of E-plane: (a) for the conventional antenna at $13 \mathrm{GHz}$; (b) for the proposed antenna at $13 \mathrm{GHz}$; (c) for the conventional antenna at $16.5 \mathrm{GHz}$; (d) for the proposed antenna at $16.5 \mathrm{GHz}$.

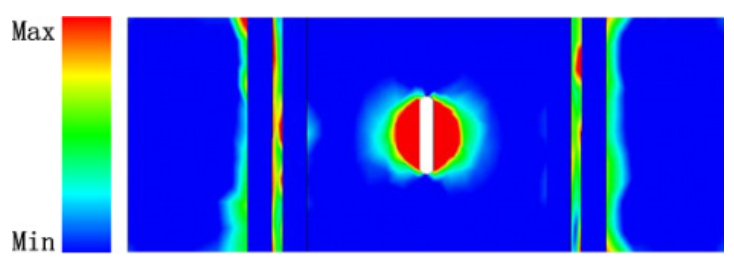

(a)

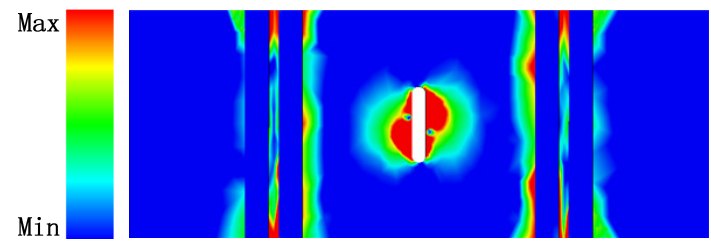

(b)

Fig. 8. The surface electric field distribution on the corrugated plate for: (a) $13 \mathrm{GHz}$; (b) $16.5 \mathrm{GHz}$.

nance frequency correspondingly, the primary source and the secondary source are constructively interfered in the far field for both frequencies as shown in Fig. 7b and Fig. 7d, leading to the improved radiation pattern.

Figure 8 shows the surface electric field distribution on the corrugated plate at $13 \mathrm{GHz}$ and $16.5 \mathrm{GHz}$. In Fig. 8a, the electric fields are gathered in the farther grooves, which means the radiation performance of lower band is affected by the grooves with larger period. While in Fig. 8b, we can find that the improvement of the upper band is resulted from the grooves with smaller period. Comparing Fig. 8a with Fig. 8b, the electric fields of each frequency are gathered in different grooves, thus the design of double-periodic corrugated plate may be independent for each frequency.

\section{Conclusions}

In this letter, a novel dual-band microstrip antenna with improved radiation performance is proposed. Taking advantage of the double-periodic corrugated plate, the improved radiation performance for each operated frequency is obtained. Through the constructive superposition of the radiated electric field by the radiating patch and the corrugated grooves, the proposed antenna achieves an improved gain of $4.7 \mathrm{~dB}$ and $5.6 \mathrm{~dB}$ at two operated frequencies respectively, and the HPBW of E-plane is reduced by 140 degrees and 130 degrees compared with the conventional antenna. Moreover, the overall profile of this antenna is reduced to $5 \mathrm{~mm}$. The proposed antenna with 
high performance will be attractive for potential applications in wireless systems like millimeter wave wireless local area networks.

\section{Acknowledgments}

The work was supported by the National Natural Science Foundation of China (No. 51477001).

\section{References}

[1] SIM, C. Y. D., CHANG, C. C., ROW, J. S. Dual-feed dualpolarized patch antenna with low cross polarization and high isolation. IEEE Transactions on Antennas and Propagation, 2009, vol. 57, no. 10, p. 3321-3324. DOI: 10.1109/TAP.2009.2028702

[2] NASIMUDDIN, CHEN, Z. N., QING, X. M. Dual band circularly polarized S-shaped slotted patch antenna with a small frequency ratio. IEEE Transactions on Antennas and Propagation, 2010, vol. 58, no. 6, p. 2112-2115. DOI: 10.1109/TAP.2010.2046851

[3] CHANG, T. N., LIN, J. M. Serial aperture-coupled dual band circularly polarized antenna. IEEE Transactions on Antennas and Propagation, 2011, vol. 59, no. 6, p. 2419-2423. DOI: 10.1109/TAP.2011.2144553

[4] BAO, X. L., AMMANN, M. J. Dual-frequency circularlypolarized patch antenna with compact size and small frequency ratio. IEEE Transactions on Antennas and Propagation, 2007, vol. 55, no. 7, p. 2104-2107. DOI: 10.1109/TAP.2007.900271

[5] EBbesen, T. W., LEZEC, H. J., GHAEMI, H. F., THIO, T., WOLFF, P. A. Extraordinary optical transmission through subwavelength hole arrays. Nature, 1998, vol. 391, no. 2, p. 667-669. DOI: $10.1038 / 35570$

[6] HUANG, C., ZHAO, Z., LUO, X. G. Application of "bull's eye" corrugated grooves integrated with artificially soft surfaces structure in the patch antenna to improve radiation performance. Microwave and Optical Technology Letters, 2009, vol. 51, no. 7, p. 1676-1679. DOI: 10.1002/mop.24443

[7] Beruete DiaZ, M., CAMPillo, I., DOLAdO, J. S., et al. Dual-band low-profile corrugated feeder antenna. IEEE Transactions on Antennas and Propagation, 2006, vol. 54, no. 2, p. 340-350. DOI: 10.1109/TAP.2005.863380

[8] Beruete DiaZ, M., CAMPILlO, I., DOLADO, J. S., et al. Very low profile and dielectric loaded feeder antenna. IEEE Antennas and Wireless Propagation Letters, 2007, vol. 6, p. 544548. DOI: 10.1109/LAWP.2007.909969

[9] QIN, K., LI, M. Q., XIA, H. M., WANG, J. A new compact aperture coupled microstrip antenna with corrugated ground plane. IEEE Antennas and Wireless Propagation Letters, 2012, vol. 11, p. 807-810. DOI: 10.1109/LAWP.2012.2208212

[10] HUANG, C., ZHAO, Z., FENG, Q., LUO, X.G. A high-gain antenna consisting of two slot elements with a space larger than a wavelength. IEEE Antennas and Wireless Propagation Letters, 2010, vol. 9, p. 159-162. DOI: 10.1109/LAWP.2010.2044863

\section{About the Authors ...}

Minquan LI was born in Anhui province, China. He is a professor of Anhui University. His research interests include microwave devices and circuits and computational electromagnetic.

Kun QIN was born in Anhui province, China. He received his M.Sc. from Anhui University, Hefei, China, in 2013. His research interests include microwave devices and circuits.

Hongqing HE was born in Anhui province, China. He is a master's candidate of Anhui University, Hefei, China. His research interests include microwave devices and circuits. 